\title{
UNRESTRICTED COMPOSITION AS IDENTITY
}

Einar Duenger Bohn (Final draft)

In Composition as Identity, eds. D. Baxter \& A. Cotnoir, Oxford University Press.

Composition as identity, as I understand it, is the thesis that a whole and all its parts collectively is the same thing under two different modes of presentation. The main virtue of the thesis is that it entails unrestricted composition, the thesis that any plurality of things composes something: the composed is the same thing as the composers so if the composers exist, ipso facto so does the composed. This provides us with a lot more entities that can play the role of denotation for our ordinary and theoretical terms, and so at no extra ontological cost.

But, as always, there are objections. So, in what follows, I first articulate a version of composition as identity (section 1). I then argue that it entails unrestricted composition, contra some objections to that effect (section 2). Finally, I argue that this result throws some new light on the more general debate over composite objects (section 3).

\section{COMPOSITION AS IDENTITY}

Identity is the primitive relation everything bears to itself and to nothing else, uniquely characterized by the following two laws: ${ }^{1}$

(R): $\forall \alpha(\alpha=\alpha)$

(PII): $\forall \alpha \forall \beta(\alpha=\beta \rightarrow \forall X(X \alpha \leftrightarrow X \beta))$

where ' $\alpha$ ' and ' $\beta$ ' are first-order variables, and ' $X$ ' is a second-order variable ranging over (extensional) properties. ${ }^{2}$ Now, let ' $\alpha=\beta$ ' be the form of our atomic (first-order)

\footnotetext{
${ }^{1}$ On the uniqueness involved, see Quine (1966:ch.16) and Williamson (2006).

2 The symmetry and transitivity of identity is deduced from R and PII, making identity the unique equivalence relation obeying PII. I formulate PII in terms of second-order quantification and henceforth talk about properties without shame,
} 
well-formed formula (wff) of identity, but with each one of ' $\alpha$ ' and ' $\beta$ ' admitting values of any cardinality. Without this last admission, composition as identity is a non-starter. But with that assumption on board, we can isolate, or define, various sub-types of expressions of identity. For example, the instances in which both ' $\alpha$ ' and ' $\beta$ ' take singular values we mark as the expressions of identity from classical first-order singular logic: $x=y$. The instances in which both ' $\alpha$ ' and ' $\beta$ ' take plural values we mark as the expressions of identity from first-order plural logic: $\mathrm{xx}=\mathrm{yy} .^{3}$ The instances in which ' $\alpha$ ' takes a plural value and ' $\beta$ ' a singular value we mark as the expressions of what we might call numerically hybrid identity: $\mathrm{xx}=\mathrm{y}$.

We then define mereological composition as follows:

(CAI): $\mathrm{xxCy}={ }_{\mathrm{df}} \mathrm{xx}=\mathrm{y}$

where ' $C$ ' is the predicate expressing composition. Since ' $\alpha=\beta$ ' is satisfied iff $v(\alpha)$ is identical with $v(\beta)$, ' $\mathrm{xx}=\mathrm{y}$ ' is satisfied iff $v(\mathrm{xx})$ is identical with $v(\mathrm{y})$, where $v$ is a primitive value assignment. Hence, by CAI, that ' $\mathrm{xxCy}$ ' is satisfied iff $v(\mathrm{xx})$ is identical with $v(\mathrm{y}) .{ }^{5} \mathrm{By}$ CAI, we then define the rest of the mereological predicates as well. Parthood: $\mathrm{x}<\mathrm{y}={ }_{\mathrm{df}} \exists \mathrm{zz}(\mathrm{zz}, \mathrm{xCy})$; proper parthood: $\mathrm{x}<<\mathrm{y}={ }_{\mathrm{df}} \mathrm{x}<\mathrm{y} \& \mathrm{x} \neq \mathrm{y}$; overlap: $\mathrm{xOy}=\mathrm{df}_{\mathrm{df}}$ $\exists \mathrm{z}(\mathrm{z}<\mathrm{x} \& \mathrm{z}<\mathrm{y})$; and disjointness: $\mathrm{xDy}=\mathrm{df} \sim \mathrm{xOy}$. By CAI, we thus need no mereological

but a nominalization should be possible without affecting my overall argument. I understand quantification objectually, so, by 'the value of a term' I henceforth mean the worldly referent of that term.

${ }^{3}$ For the details of the plural logic I employ, see Yi $(2005,2006)$. Like Yi, I take plural reference to be irreducible, and allow a plural term to be assigned a plurality of one or more things as its value.

${ }^{4}$ Note that we also have the case of ' $y=x x$ ', so we need to restrict our formal system in order to avoid getting that $\mathrm{yCxx}$ (which is mereological nonsense) by virtue of CAI and the symmetry of identity. CAI should only allow us to substitute ' $\mathrm{x} x=\mathrm{y}$ ' with ' $\mathrm{xxCy}$ ', not ' $\mathrm{y}=\mathrm{xx}$ ' with ' $\mathrm{yCxx}$ '. Note also that the identity involved is a collective relation, not a distributive one.

${ }^{5}$ Many will already suspect that a singular value cannot be the same as a plural value of two or more things, so expressions of the form ' $\mathrm{xx}=\mathrm{y}$ ' must always be false if $v(\mathrm{xx})$ is two or more things, and hence, by CAI, expressions of the form ' $\mathrm{xxCy}$ ' must also always be false if $v(\mathrm{xx})$ is two or more things, which results in mereological nihilism, the view according to which there are no composite objects. But see below. 
primitive, which makes for a simpler ideology, which seems a theoretical and metaphysical virtue. ${ }^{6}$ I henceforth take CAI and all it involves to express the thesis of Composition as Identity. In particular, the above satisfaction-conditions (and hence truth-conditions) for wffs of the form "xx=y" and "xxCy" (and their closures) are crucial to how I understand the thesis of composition as identity. Without these conditions, I don't know what the thesis of composition as identity is. ${ }^{7}$

Sometimes one finds composition as identity formulated in terms of a material biconditional: 8

$\left(\mathrm{CAI}^{*}\right): \mathrm{xxCy} \leftrightarrow \mathrm{xx}=\mathrm{y}$

But such a formulation is too weak. For all CAI* says, it could be the case that ' $\mathrm{C}$ ' and '=' express two distinct relations that just happens to be such that their extensions overlap, but which might, in other possible worlds, fail to be thus related. We thus open up all the room for doubt about composition really being a relation of identity. Merely necessitating CAI* doesn't seem to fully resolve the worry of the two relations being distinct. I therefore prefer the stronger formulation in terms of a definition. This way there is no room for doubt as to whether ' $C$ ' and ' $=$ ' express the same relation. Of course, it raises the difficult question as to whether the definition $('=\mathrm{df}$ ') expresses a mere stipulation as to how to use 'C', or some kind of analysis of our concept of a composite object. I am not entirely sure how to answer this question at this point, but let's just note for now that CAI, as opposed to CAI*, does have the virtue of better tying ' $C$ ' to identity as well as simplifying ideology (the latter perhaps being the most important of the two). The question of how to interpret the definition involved in CAI will briefly come up again in section 3 .

${ }^{6}$ On the virtue of simplifying ideology, see Sider $(2011,2013)$.

7 I pick up the lead from Lewis $(1988,1991,1993 a)$ and Bohn (2009), but different versions of it are found in Armstrong (1978, 1997), Baxter (1988a, 1988b), Wallace (2011a, 2011b) and Cotnoir (forthcoming).

8 For example, Sider (2007) and (this volume). 
Some might suspect that CAI is simply incoherent. Assume a,b compose c. By CAI, $a, b=c$. By PII, any property of $a, b$ is then a property of $c$, and vice versa. But, for example, a,b has a cardinal property greater than 1 , which $\mathrm{c}$ does not; $\mathrm{a}, \mathrm{b}$ form a many-membered set, which $\mathrm{c}$ does not; and $\mathrm{a}, \mathrm{b}$ has the property of having $\mathrm{b}$ as one of them, which c does not. So, by virtue of PII, CAI seems to lead to paradox.

But what goes wrong in each of these cases is that we forget to consider the mode of presentation, or concept under which we think of the things of which we make our predications. No ordinary thing has a particular cardinality independent of how it is conceptualized. Frege (1884) stressed this in various ways, perhaps most famously by the case of a deck of cards. I can hold one and the same thing in my hand and truly say of it that it is 1 deck of cards, but 52 cards. One and the same thing is thus 1 when thought of under (or picked out by) the concept DECK OF CARDS, but 52 when thought of under (or picked out by) the concept CARD. From such cases Frege concluded that cardinality must be a property of (or in his words: "attaches to") concepts, not the things falling under the concepts. But for present purposes this is insufficiently general because we must consider the other paradoxical cases as well. It makes little sense to say that forming a set is a relation that only holds of concepts. In the case of impure sets, it is usually the things that fall under a concept that are members of and form a set, not the concept. So, it is better to say that in all "problematic" cases of the same kind as the three above, i.e. in all cases of predication whose truth depends on a unique kind of "division" or "decomposition" of the value of the subject term, the properties and relations hold relative to concepts, not of concepts. ${ }^{9}$ This way the road to the above paradoxes is immediately blocked: having a property $F$, or standing in a relation $R$, relative to $C_{1}$,

\footnotetext{
${ }^{9}$ Sider (2007:59) calls it "set-like" predications. The predication 'is $n$ in number' is a paradigm case of such a set-like predication since its truth depends on a particular kind of "decomposition" of the value of the subject term, namely into $n$ things. The predication 'has mass $m$ ' is a good case of a non-set-like predication since it doesn't matter how we "divide" the value of the subject term; it (collectively) has the same mass either way (assuming mass is additive).
} 
but not having it or standing in it relative to $\mathrm{C}_{2}$ is no paradox. A formula of the form $\mathrm{F}\left(\mathrm{x}_{1}, \ldots, \mathrm{X}_{\mathrm{n}}, \mathrm{C}_{1}\right) \& \sim \mathrm{F}\left(\mathrm{x}_{1}, \ldots, \mathrm{x}_{\mathrm{n}}, \mathrm{C}_{2}\right)$ is no contradiction. ${ }^{10}$

With such a relational structure to all the problematic cases, we can also block the Yi-Sider argument from CAI to the misbehavior of the predicate 'is one of' (and other plural resources). ${ }^{11}$ The argument for the misbehavior of 'is one of' rests explicitly on employing PII without considering the relational unit involved in the problematic predications. Here is Yi's (1999:146) version. ${ }^{12}$ We let Genie be the fusion of Tom and Jerry. By CAI, Tom,Jerry=Genie. Since Genie is one of Genie, by PII, Genie is one of Tom,Jerry. But by the obvious truth that $a$ is one of $b_{1} \ldots b_{n}$ iff $a=b_{1}$ or ... or $\mathrm{a}=\mathrm{b}_{\mathrm{n}}$, Genie is not one of Tom,Jerry. Contradiction. So, either CAI is false or 'is one of' cannot behave as expected by violating the obvious truth that a is one of $b_{1} \ldots b_{n}$ iff $a=b_{1}$ or $\ldots$ or $a=b_{n}$.

According to the above strategy, the argument is blocked because it misapplies PII. Though Genie=Tom,Jerry, the phrase "Genie is one of..." does not express the same property in "Genie is one of Genie" as it does in "Genie is one of Tom,Jerry": there are different concepts functioning as the relational unit in the two

10 This kind of solution, in some form or other, is briefly discussed, but dismissed in Sider (2007:68-69), and defended in Bohn $(2009,2011)$ and Cotnoir (forthcoming). Sider discusses the case with properties taking the place of my concepts, while Cotnoir discusses the case with so-called counts in the place for my concepts. By using concepts as the relational units instead of properties or counts, I arguably avoid Sider's worry that appealing to properties removes the property-nominalistic motivations for the employment of Boolos's $(1984,1985)$ plural logic, as well as Cotnoir's employment of set theory in order to articulate CAI (though, according to Cotnoir, sets can be dispensed with in favor of hyperplural resources). Presumably, concepts, in some sense or other, are indispensible, even if properties / sets / hyperplurals are not. Note further that there need not be a token concept functioning as the relational unit for each case of a relational predication, but rather there might be a type of concept for each such case, namely a type of concept that provides the right kind of "decomposition", "division", or "slicing up" of the value of the subject term. Finally, identity itself is of course not thus relational. Relative identity is worse than death.

${ }^{11}$ See Yi (1999) and Sider (2007, this volume).

12 My reply to Yi's version of the argument carries equally well over to Sider's (2007, this volume) versions of it. 
cases. What we can truly say of a thing often (but not always) partly depends on how we conceptualize it.

Many problems remain of course. Exactly which properties are thus relational and which are not? ${ }^{13}$ There is no reason to expect a clear-cut line. Must we quantify over, and hence commit to the existence of concepts? Maybe, but at some point we must perhaps stop quantifying over whatever we use in our theories on pain of impredicative, or self-referential paradoxes. From where do the relational units (concepts) come into play? Most likely, they come from a context of use. But what about purely quantificational formulas such as " $\forall x x \exists y(y$ is one of $x x)$ ": which context of use selects the needed concept to play the relational role here? ${ }^{14}$ Most likely, there is here an implicit existential quantification over contexts of use, perhaps informed by the description of the model over which we interpret the quantifiers. ${ }^{15}$ Finally, does invoking concepts as relational units entail some form of mind-dependence or lack of objectivity with respect to the relational properties? Only to the extent concepts are mind-dependent or lack objectivity, which I take it, in good Fregean spirit, they aren't and don't.

In any case, I must leave all these and other problems aside for now. For present purposes, I simply assume they can be satisfactorily solved somehow. On that assumption, I argue that unrestricted composition follows from the present version of composition as identity.

\section{UNRESTRICTED COMPOSITION}

The following is a simple derivation in the standard quantificational logic of identity:
1. $\forall \alpha(\alpha=\alpha)$
$\mathrm{R}$
2. $\alpha=\alpha$
$1, \forall \mathrm{I}$
3. $\exists \beta(\alpha=\beta)$
$2, \exists G$

13 Or: what exactly is a "set-like" property?

${ }^{14}$ These last two points are made in Sider (2007:68-69).

${ }^{15}$ Without an explicit or implicit description of such models, the purely quantificational wffs are of course just meaningless inscriptions. 

4. $\forall \alpha \exists \beta(\alpha=\beta)$
$3, \forall G$

Since the values assigned to ' $\alpha$ ' and ' $\beta$ ' can be either singular or plural, we can as above mark the following three versions of 4: (4a) $\forall x \exists y(x=y)$; (4b) $\forall x x \exists y y(x x=y y)$; and (4c) $\forall x x \exists y(x x=y)$. But from $4 c$ it follows by definition that:

\section{5. $\forall x x \exists y(x x C y) \quad 4 c, C A I$}

which is unrestricted composition. By Necessitation, we get the necessity of unrestricted composition.

The step from 4 to $4 \mathrm{a}$ is justified by the following instance of the argument 14: (1a) $\forall x(x=x)$; hence (2a) $x=x$; hence (3a) $\exists y(x=y)$; hence (4a) $\forall x \exists y(x=y)$. The step from 4 to $4 \mathrm{~b}$ is justified by the following instance: (1b) $\forall x x(x x=x x)$; hence (2b) $x x=x x$; hence (3b) $\exists y y(x x=y y) ;$ hence (4b) $\forall x x \exists y y(x x=y y)$. And the step from 4 to $4 c$ is justified by the following instance of the argument: (1c) $\forall \mathrm{xx}(\mathrm{xx}=\mathrm{xx})$; hence (2c) $x x=x x$; hence (3c) $\exists y(x x=y)$; hence (4c) $\forall x x \exists y(x x=y) \cdot{ }^{16}$

The only plausible escape route from this argument seems to be the step from 2c to 3c, what Sider (2007:61) calls "the dodgy move." Because, in one sense, a step of the kind from $2 \mathrm{c}$ to $3 \mathrm{c}$ is simply invalid, witnessed by the following case. Assume our domain of interpretation consists of the objects a,b,c,d, and that a,b,c collectively surround d. That is, a,b,c surrounds $d$ together, not each one by itself. Then, if our singular existential quantifier is only allowed to range over $a, b, c$ and $d$ individually, but not collectively, there is no one thing in our domain that surrounds $d$, so we cannot conclude that $\exists x$ ( $x$ surrounds $d$ ) because we have no value from our domain to assign to ' $x$ ' in that case.

But there is another sense in which there is something in our domain that surrounds d: whatever the value of the plural term 'a,b,c' is, that value must be

\footnotetext{
16 By similar reasoning, we also get the case of (4d): $\forall x \exists y y(x=y y)$. Like $4 a$ and $4 b, 4 d$ is uncontroversial, given that the plural logic is interpreted as above, according to which $v(\mathrm{yy})$ can be one or more things.
} 
something on pain of the term 'a,b,c' being denotationless. But whatever the value is, it surrounds d. So, if we let our singular existential quantifier range over $a, b, c, d$ individually and collectively, there is a sense in which we must conclude that $\exists \mathrm{x}$ ( $\mathrm{x}$ surrounds d), namely the value of the plural term 'a,b,c'. It is this latter sense that provides the kind of rationale for the step from $2 \mathrm{c}$ to $3 \mathrm{c}$, and hence from 4 to $4 \mathrm{c}$, and hence from 4 to 5 : whatever value is assigned to ' $\mathrm{xx}$ ' in step 2c, that very same value is also assigned to ' $y$ ' in step 3c, albeit under a different concept.

But isn't it possible that the value of ' $x x^{\prime}$ in step 2c just isn't one thing, and hence that it just cannot legitimately be assigned to ' $y$ '?

This last point is what lies behind a recent objection to the claim that CAI entails unrestricted composition. Peter van Inwagen (1994) seems to be the first to present the objection. David Lewis (1991:3.6) claims that the ontological commitment to a composite object and the ontological commitment to all its parts collectively is one and the same ontological commitment. Mereological composition is therefore, according to Lewis, ontologically innocent (and therefore unrestricted). But van Inwagen (1994:102-103) objects to this idea of innocence as follows. I can ontologically commit myself to some things collectively as follows: "I hereby ontologically commit myself to the existence of a,b,c." I can also ontologically commit myself to the same things collectively as follows: "I hereby ontologically commit myself to the existence of a; I hereby ontologically commit myself to the existence of b; and I hereby ontologically commit myself to the existence of c." But by either such way of ontologically committing myself to the existence of these things collectively, I only commit myself to the existence of a,b,c. No one of the ways is committing myself to the existence of a composite having a,b,c as parts.

van Inwagen goes on to immediately provide a similar objection in terms of quantification. Suppose I am to evaluate the truth-value of a bunch of existentially quantified sentences interpreted over a domain consisting of a,b,c and the thing they compose, d. How many things must I consider in order to determine the truthvalues of my existentially quantified sentences? Four, namely a,b,c,d. But if d just is 
a,b,c, we only have three things to consider in order to determine the truth-value of my existentially quantified sentences, not four.

van Inwagen's point is simple: if committing to a,b,c collectively is just the same as committing to $\mathrm{a}, \mathrm{b}$ and $\mathrm{c}$, then committing to them just isn't committing to some fusion of them that is identical with neither one of them; and if our domain consists of a,b,c and the thing they compose d, we must consider all four of them whenever we evaluate existentially quantified sentences, not just $a, b$ and $c$. Either way, we just don't get composite objects for free; we must commit to them individually, which just isn't an ontologically innocent move.

We can easily see how this amounts to a denial of the step from $2 c: x x=x x$, to $3 c$ : $\exists y(x x=y)$. First, if we assign the plurality a,b,c to ' $x x^{\prime}$ in $2 c$, there is thereby a form of ontological commitment to a,b,c, but not to any composite they make up. But then step $3 \mathrm{c}$ might not be satisfied even though $2 \mathrm{c}$ is satisified, which means the step is invalid. Second, if d just is a,b,c, there really is only a,b,c to consider for existence. But then step $2 \mathrm{c}$ is satisfied by assigning a,b,c to ' $\mathrm{xx}$ ', but step $3 \mathrm{c}$ is not satisfied by there not being any one thing identical with $a, b, c$, since we really only have $a, b, c$ to consider and no "fourth" thing d. So, again, the step from $2 \mathrm{c}$ to $3 \mathrm{c}$ is invalid.

Ross Cameron (2012) presents a similar objection. He argues that even though every plurality is self-identical, if CAI is conceptually coherent, it is also conceptually coherent to hold that some pluralities are not identical with any one thing. In other words, step $2 \mathrm{c}$ might be satisfied, without step 3c being so, which means that the step from $2 \mathrm{c}$ to $3 \mathrm{c}$ is invalid. ${ }^{17}$

The soundness of this kind of objection rests on how we understand the quantifier involved. Arguably, quantification is best understood in terms of generalized

${ }^{17}$ It should be noted that Cameron discusses the bi-conditional CAI*, not the definitional CAI. It seems to me that what Cameron says does not always carry over to CAI, as opposed to CAI*. For example, by virtue of CAI and the defense of $1 \mathrm{c}-4 \mathrm{c}$ below, it is not conceptually coherent to hold that some things are not identical with one thing, contra what Cameron claims. So, a proponent of CAI has a way to reject Cameron's argument that might not be available to a proponent of CAI*. 
quantification, as per standard contemporary formal semantics. ${ }^{18}$ For present purposes, the rough idea is that the semantic value of a quantifier is a property of (n-place) properties. In the particular case of the existential quantifier, the idea is that its semantic value is a property of properties that are instantiated. So, ' $\exists \alpha F \alpha$ ' is true iff the property $F$ has the property of being instantiated. ${ }^{19}$

But this last case is only a generic case of existential quantification. The case is generic in the sense of our system of identity presented at the outset, and our derivation 1-4 above: it is abstracted away from, or remain neutral between more particular ways of existentially quantifying; for example, the singular way $(\exists x F x)$ and the plural way $(\exists \mathrm{xxFxx})$. In order to be able to separate these last two cases from each other, we must fill in the story as follows: ' $\exists x F x$ ' is true iff the property $F$ has the property of being instantiated by an object; and ' $\exists x x F x x$ ' is true iff the property $F$ has the property of being instantiated by a plurality of objects.

Obviously, each one of these two particular cases entails the generic case: if ' $\exists x F x$ ' is true, ' $\exists \alpha F \alpha$ ' is true; and if ' $\exists x x F x$ ' is true, ' $\exists \alpha F \alpha$ ' is true. This is so because if the generic case is false, then $F$ doesn't have the property of being instantiated, and hence doesn't have the property of being instantiated by either an object or a plurality of objects; so, contrapositively, if $F$ has the property of being instantiated by either an object or a plurality of objects, it also (in either case) has the property of being instantiated. But the generic case doesn't entail the singular or the plural case: ' $\exists \alpha F \alpha$ ' might be true without ' $\exists x F x^{\prime}$ being true, and ' $\exists \alpha F \alpha$ ' might be true without ' $\exists x x F x x$ ' being true (except, perhaps, when $v(\mathrm{xx})$ is just one thing, which we can here ignore).

We can now re-state our initial objection: even though we get from ' $\mathrm{x} x=\mathrm{xx}$ ' to ' $\exists \alpha(x x=\alpha)$ ', we don't get from ' $\exists \alpha(x x=\alpha)$ ' or ' $x x=x x^{\prime}$ to ' $\exists y(x x=y)$ '; hence the move

18 See Mostowski (1957), Lewis (1970), Montague (1973), Barwise \& Cooper (1981), Heim \& Kratzer (1998), Portner (2005) or Westerståhl (2007). The idea behind generalized quantification comes from Frege; e.g. Frege (1892).

${ }^{19}$ In terms of a standard set-theoretical interpretation, which I don't employ here, this amounts to saying that ' $\exists \alpha \mathrm{F} \alpha$ ' is true iff the set of all Fs is a member of the set of all non-empty subsets of the given domain. 
from $2 \mathrm{c}$ to $3 \mathrm{c}$ is invalid. But the soundness of this objection can be seen to depend on putting metaphysical commitments into the argument that simply aren't there. Consider the formula $2 \mathrm{c}$ again: $\mathrm{xx}=\mathrm{xx}$. Under what conditions is it satisfied? It is satisfied iff the same value is assigned to both variables flanking the identity sign, i.e. iff $v(\mathrm{xx})$ is identical with $v(\mathrm{xx})$. Now, consider the property $\lambda z[v(x x)=z]$, i.e. the property of being (the thing that is) identical with the value of ' $\mathrm{xx}$ ' (for arbitrary $v(\mathrm{xx}))$. And consider the following three cases:

(2ci): $\lambda z[v(x x)=z]$ has the property of being instantiated

(2cii): $\lambda z[v(x x)=z]$ has the property of being instantiated by an object

(2ciii): $\lambda z[v(x x)=z]$ has the property of being instantiated by a plurality of objects

If $2 \mathrm{ci}$ is true, the generic version of $3 \mathrm{c}$ follows: $\exists \alpha(\mathrm{xx}=\alpha)$. If $2 \mathrm{cii}$ is true, the singular version of $3 \mathrm{c}$ follows: $\exists \mathrm{y}(\mathrm{xx}=\mathrm{y})$. If 2 ciii is true, the plural version of $3 \mathrm{c}$ follows, i.e. $3 \mathrm{~b}$ : $\exists y y(x x=y y)$. The above objection cannot be rejecting that 2ciii is true (on pain of rejecting trivialities in the standard plural logic of identity). But as we saw above, if either one of 2cii and 2ciii is true, then 2ci is true as well: the singular and plural cases entail the generic case. So, the objector cannot reject $2 \mathrm{ci}$ (on pain of having to reject 2ciii after all). That leaves her with 2cii only.

But 2 cii is as ambiguous as the term 'object' is. No one should reject that, for example, three existing scattered simples a,b,c is a less natural sort of object than one simple. ${ }^{20}$ But likewise, no one should reject that a,b,c exist; after all, that $a, b, c=a, b, c$ entails that $\exists y y(a, b, c=y y)$. But, as we have seen, that $\exists y y(a, b, c=y y)$ entails that $\exists \alpha(a, b, c=\alpha)$, which must mean that a,b,c are identical to something from our domain, whatever it is. But then we have at least two different ways of understanding the term 'object' in 2cii: one according to which an object is something belonging to a more or less natural sort of thing; and another according

${ }^{20}$ By 'sort' I just mean a kind of objects by virtue of some property they have in common. By 'more or less natural sort' I just mean a sort by virtue of some more or less natural property. On naturalness, see Lewis (1983a, 1986:59-69) and Sider (2009). 
to which it is not, but rather just something we can singularly quantify over, however unnatural sort of thing it is. For obvious reasons, let's call the first notion thick and the second notion thin. The objector to the step from $2 \mathrm{c}$ to $3 \mathrm{c}$ must be having something like the thick notion in mind. But obviously no proponent of CAI has the thick notion in mind. So, to the extent there is an objection to CAI here, it either changes the subject or begs the question. When the proponent of CAI claims, for example, that three arbitrary scattered simples compose something, he is of course not claiming that what the three simples compose belong to some natural sort of things. After all, the three simples can be as scattered and gerrymandered as they can be (and a collection of Fs need not compose an F). He is only claiming that there exists something that is identical with them, no matter how unnatural it is. ${ }^{21}$ That is, for a proponent of CAI, the truth of 2 cii only requires the truth of $2 \mathrm{ci}$ : there is an object there if there is something there. But, as we have seen, the falsity of $2 \mathrm{ci}$ is inconsistent with the truth of 2 ciii. So, by the obvious truth of 2 ciii, 2 ci follows. But then, if the truth of 2cii only requires the truth of 2ci (due to the thin notion of an object), 2cii follows too. But 2cii entails 3c, so, by CAI, 2ciii entails 3c, which means that, by CAI, unrestricted composition follows (since 3c entails 4c, which entails 5).

I suspect some might immediately object that the move just made from $2 \mathrm{ci}$ to 2cii is precisely what is invalid: just because a property has the property of being instantiated it doesn't mean it has the property of being instantiated by an object. But, again, if by 'object' one means something, which is the thin notion of what an object is, there is simply no room to deny it because if $v(x x)$ is not something, ' $x \mathrm{x}=\mathrm{xx}$ ' is not satisfied, which contradicts the assumption that ' $\mathrm{xx}=\mathrm{xx}$ ' is satisfied.

The whole argument can thus be succinctly summed up as a reductio. ${ }^{22}$ Assume we have a model according to which ' $\mathrm{xx}=\mathrm{xx}$ ' is satisfied, but ' $\exists \mathrm{y}(\mathrm{xx}=\mathrm{y})$ ' is not satisfied. Then, $v(\mathrm{xx})$ is identical with $v(\mathrm{xx})$, but it is not the case that there is

\footnotetext{
${ }^{21}$ As Sider (2009:406) nicely puts it: "Intuitively, what is unnatural about this object is its nature, not its being."

${ }^{22}$ The model-talk is not to be understood set-theoretically. I here consider a domain to be a mere plurality, not a set (or class), and I consider a function to be a rulegoverned assignment, not a set-theoretical construction.
} 
something from our domain identical with $v(\mathrm{xx})$. But, by assumption, $v(\mathrm{xx})$ is identical with $v(\mathrm{xx})$, so there is something from our domain identical with $v(\mathrm{xx})$, namely $v(\mathrm{xx})$. Contradiction. Hence, if ' $\mathrm{x} x=\mathrm{xx}$ ' is satisfied, then ' $\exists \mathrm{y}(\mathrm{x} x=\mathrm{y})$ ' is satisfied too. Hence, $2 c$ entails $3 c$, which means that 4 entails 5 , which means that CAI entails unrestricted composition. To be something is to be the value of any variable!

Just to repeat myself: this argument is not equivocating on 'something', but rather unequivocally employing a thin notion throughout. An objection based on the thick notion is thus either changing the subject or begging the question.

Let me end this section by replying to some further objections. First, one might insist that if really, most fundamentally speaking, $v(\mathrm{xx})$ is two or more things, then $v(\mathrm{xx})$ is not also one thing, so, really, most fundamentally speaking, even though ' $x \mathrm{x}=\mathrm{xx}$ ' is satisfied, ' $\exists y(x x=y)$ ' need not be, which means the step from $2 c$ to $3 c$ is invalid (really, most fundamentally speaking).

What underlies this kind of objection is a notion of fundamental reality - a notion of what and how reality is, really, as opposed to more casual but somehow still "correct" ways of saying what and how it is - and furthermore that fundamental reality as such is the proper domain of interpretation for our quantifiers, at least in the idiolect of professional ontology. ${ }^{23}$ Now, this objection is just a variant of the earlier one with the thick notion of what an objects is, namely something of some more or less privileged sort. But it might nonetheless be worth briefly showing that not even the existential quantifier interpreted as ranging over fundamental reality blocks my argument from CAI to unrestricted composition. There is a very natural sense in which any plurality of things composes something that exists even in a fundamental sense of 'exist'.

${ }^{23}$ Cf. Dorr (2005) and Sider $(2009,2011)$. I henceforth understand 'fundamental' and 'natural' as primitives, not necessarily co-extensional. On naturalness, see Lewis (1983a, 1986:59-69). Intuitively, fundamentality is "being at the bottom", or "that which everything else holds in virtue of", while naturalness is "carving at the joints". Arguably, these notions can cut across each other. I suspect that some such notion of fundamentality, at least implicitly, lies behind both van Inwagen's (1994) and Cameron's (2012) objection discussed above. 
By generalized quantification, ' $\exists \alpha F \alpha$ ' is true iff the property $F$ has the property of being instantiated, so, plausibly, ' $\exists \alpha F \alpha$ ' is fundamentally true if the property $F$ is fundamental and has the property of being instantiated. Nothing more is needed for fundamental existence as such. ${ }^{24}$ So, in particular, 'Эy(xx=y)' is fundamentally satisfied if the property of being identical with $v(\mathrm{xx})$ is fundamental and has the property of being instantiated by something. But surely identity is fundamental, and, for an arbitrary domain, being identical with $v(\mathrm{xx})$ is indeed instantiated by something, namely $v(\mathrm{xx})$ itself, so it follows by similar reasoning as above, that ' $\exists \mathrm{y}(\mathrm{xx}=\mathrm{y})$ ' is fundamentally satisfied. Fundamental existence as such is insensitive to what perfectly natural sorts of things there are. So, for any plurality of things, they compose something that fundamentally exists. Modifying my argument to only deal with fundamental quantification does not remove its validity. ${ }^{25}$

One might object that self-identity is not the right kind of fundamental property, and hence that the above argument doesn't get us the right kind of fundamental existence. But, first of all, what can it possibly mean to say that selfidentity is not the right kind of fundamental property? Certainly it is something conceptually basic holding of everything whatsoever. What more can we require for some property to be a fundamental property of the right kind? Must it also have a non-empty complement? Self-identity, like existence, doesn't have a non-empty complement. So, in one sense, it is indeed special. But why does it disqualify it from being a fundamental property of the right kind? Why must a fundamental property of the right kind have a restricted extent? In fact, there is a sense in which a property of self-identity holding of everything whatsoever is, like existence, of exactly the right kind of fundamental property, namely the one according to which

\footnotetext{
24 I hope to further defend this position elsewhere, but note for now that existence as such is one thing; what sort of thing it is, is another.

25 There are of course other notions of fundamental quantification out there for which this argument will not work as smoothly, but, as far as I can tell, the notion of a fundamental quantifier that I just provided is very natural, straightforward, and what we get from how quantification is understood in standard formal semantics. But it amounts to something "less" than what you find in e.g. Sider $(2009,2011)$, where more metaphysical content is built into it.
} 
every plurality whatsoever instantiates it, and hence the one according to which every plurality whatsoever is something that we cannot explain by virtue of anything else. To me at least, that seems fundamental if anything is.

Finally, one might object that the thesis of composition as identity as such does not entail unrestricted composition because by merely adding a thick notion of quantification the conclusion fails to go through. ${ }^{26}$ But it's just not clear what the 'as such' locution means in that case. There is no one thesis of composition as identity out there that everyone agrees is it. Rather, there are many different versions of it floating around. ${ }^{27}$ By adding a thick notion of existential quantification to my argument one isn't merely adding something to it, but rather changing its main premise, namely $\mathrm{CAI}$, to become some other, different premise, say CAI** $\left(\mathrm{CAI} \neq \mathrm{CAI}{ }^{* *}\right)$. A general problem with the van Inwagen-Cameron objection is that it is not clear exactly what the target is. All I argue is that my version of composition as identity avoids the objection and in fact entails unrestricted composition.

This last reply brings out a reply to Kris McDaniel's (2010) different objection to the claim that composition as identity entails unrestricted composition. McDaniel's objection is that three mutually coherent theses jointly entail both composition as identity and the falsity of unrestricted composition, so composition as identity cannot itself entail unrestricted composition on pain of paradox. The three theses are (i) moderate pluralism: there exists at least two disjoint things; (ii) mereological nihilism: some things $\mathrm{xx}$ compose something y iff $v(\mathrm{xx})$ is a plurality of one and only one thing, and (iii) property extensionalism: two necessarily co-

\footnotetext{
26 By monotonicity, a valid argument doesn't become invalid by adding premises. So, if adding a premise to my argument makes the conclusion false, my argument must be invalid.

27 Compare Armstrong (1978, 1997), Baxter (1988a, 1988b), Lewis (1991), Bohn (2009), Wallace (2011a, 2011b) and Cotnoir (forthcoming). There is not much common to all of them apart from a slogan desperately in need of an interpretation. Though the most related theses, I believe, are those found in Lewis (1991), Bohn (2009) and Cotnoir (forthcoming), except Cotnoir's version uses set theory in its formulation, which in my mind (and I believe in Lewis's (1991, 1993b) mind too) gets the conceptual order wrong. Lewis is often interpreted as holding a much weaker version of composition as identity than what I have defended above, but I disagree. See Bohn (2011).
} 
extensional properties are one and the same property. That (i)-(iii) are mutually coherent seems pretty clear, so I have no wish to contest that; that (i)-(iii) jointly entails the falsity of unrestricted composition is provable, so I have no wish to contest that; but that (i)-(iii) jointly entails composition as identity; that I wish to contest. McDaniel's argument for this last point is this: by (ii), composition and identity are necessarily co-extensional relations, so by (iii) they are one and the same relation. According to McDaniel, there is no better formulation of composition as identity than what we get from thus identifying the composition relation and the identity relation with each other. But " $\mathrm{xxCy}=\mathrm{df}_{\mathrm{df}} \mathrm{x}=\mathrm{y}$ " is just a bad definition of composition as identity in the sense of not at all capturing what is intended. The good definition is CAI: " $\mathrm{xxCy}=\mathrm{df} \mathrm{xx}=\mathrm{y}$ ", which is not entailed by (ii) and (iii), given that $v(\mathrm{xx})$ can be two or more things. So, (i)-(iii) do not jointly entail composition as identity as that thesis is presently understood. ${ }^{28}$

\section{LOGIC VS. METAPHYSICS}

There seems to be a bifurcation in the literature on how to understand mereological expressions. Leonard \& Goodman (1940:45) begin their seminal work by saying that:

An individual or whole we understand to be whatever is represented in any given discourse by signs belonging to the lowest logical type of which that discourse makes use. What is conceived as an individual and what as a class is thus relative to the discourse within which the conception occurs.

And they (1940:55) end it by saying that:

...because it provides means for treating many varied entities by means of concepts of a single logical type, the calculus of individuals is a powerful and expedient instrument for constructional work. In addition it performs the important service of divorcing the logical concept of an individual from metaphysical and practical prejudices, thus revealing that ... wholes is capable of a purely formal definition, and

\footnotetext{
${ }^{28}$ McDaniel (2008) presents another objection to composition as identity, to which I reply in Bohn (2012).
} 
that ... all the concepts of logic, are available as neutral tools for the constructional analysis of the world.

Clearly, they don't intend their existential quantifier to only range over some natural sorts of things, or objects in some thick sense of the term. For them, mereology is not at all about the nature of the things it deals with, only with different ways of conceptualizing what already exists.

David Lewis seems to have picked up on such an understanding of mereological expressions when he claims that mereology is ontologically innocent (1991:81-87), much like logic (1991:62). ${ }^{29}$ Peter van Inwagen (1990:52) on the other hand, does not have such an understanding of mereological expressions in mind when he claims that

Certain formal systems (descended either from Lesniewski's "mereology" or the Leonard-Goodman "Calculus of Individuals") include among their axioms something very much like 'For any xs, those xs have a sum'. These formal systems express, on their intended interpretations, substantive metaphysical theories.

Clearly, van Inwagen's claim that Leonard \& Goodman's system of mereology on its intended interpretation expresses substantive metaphysical theories is incompatible with Leonard \& Goodman's own words on how to understand their system. ${ }^{30}$

Now, I have argued that CAI must be understood on the basis of a thin notion of existential quantification. This fits nicely with the Leonard-Goodman-Lewis-view of mereological expressions as expressions of logic (namely identity). I also argued that the main objection to my argument that CAI entails unrestricted composition seems based on a thick notion of existential quantification. This fits nicely with the van Inwagen-view of mereological expressions as expressions of more particularly committing metaphysics. But then the proponent and the opponent of the argument

29 One of Lewis's (1991:73:fn.5) references on mereology is of course Leonard \& Goodman (1940) (not that that indicates much).

${ }^{30}$ Admittedly, there is an issue here as to what is meant by 'the intended interpretation', but I cannot go into that here. 
from section 2 to the effect that CAI entails unrestricted composition are, in one sense, talking past each other. They seem to mean different things by the same (syntactic) expressions. To the proponent of my argument, the opponent is thus either changing the subject or begging the question.

But if one is willing to bring on board the two primitive notions of fundamentality and naturalness, there is a sense in which they can both be right. We let, roughly, the fundamental properties be the properties whose instantiations don't hold in virtue of the instantiation of any other properties; and we let, again roughly, the more or less natural predicates be the predicates that more or less carve out reality by its objective joints. Arguably, the two notions are nonequivalent. On the one hand, as argued above, the properties being self-identical and exist seem fundamental, but their predicates do not seem to particularly carve out any of reality's objective joints. On the other hand, many less-than-perfectly natural predicates, e.g. a predicate for some perfectly determinate shade of red, seem to carve out objective joints in nature, but don't (presumably) express fundamental properties. In any case, let's assume for the sake of argument that fundamentality and perfect naturalness can cut across each other. ${ }^{31}$

Now, consider this question: what is the mereological structure of the most natural sorts of things there are? That is, you group things into natural kinds by virtue of some most natural (sortal) properties, and then ask: what is the mereological structure of those kinds of things? As a toy case, assume the perfectly natural sorts of things are certain types of quarks, and that quarks have no proper parts. Then, we get the following possibility: by CAI, any plurality of things composes something that fundamentally exists, but nonetheless the perfectly natural sorts of things are quarks, which are mereological simples. No plurality of

\footnotetext{
${ }^{31}$ Of course, my argument in section 2 doesn't depend on this assumption. Anyone hostile to the notions of fundamentality and naturalness can still accept my argument to the effect that CAI entails unrestricted composition. Note that it is somewhat plausible that all perfectly natural predicates express fundamental properties (though I would not bet on it), even though not all fundamental properties carve out any particularly natural joint in nature.
} 
two or more quarks is identical with, and hence composes a quark. So, the result is a form of fundamental universalism coupled with a perfectly natural nihilism.

In general, if what the perfectly natural sorts of things are can vary from one possible world to another, then since the logic of identity cannot thus vary, the result is a form of necessarily true fundamental universalism coupled with a contingently true perfectly natural restrictionism. ${ }^{32}$

This last result is worth exploring a bit more by considering the two most promising arguments for the fundamental truth of mereological nihilism, namely those of Cian Dorr (2005) and Ted Sider (2013). It turns out that both arguments are invalid by virtue of supporting CAI's form of universalism just as much as, if not better than nihilism. But instead of rejecting their arguments full stop, or CAI for that matter, we might take them to be arguments to the claim that the mereological structure of the perfectly natural sorts of things is that of simples, which by the above result doesn't contradict CAI's fundamental truth of universalism.

The language of professional ontology, what is sometimes called Ontologese, is a language intended to somehow best represents the fundamental structure of reality. Dorr (2005:269) identifies this language by the following criterion:

The language of ontology is one in which all metaphysically analytic truths can be transformed into logical truths by replacing non-logical expressions with their metaphysical analyses, and replacing semantically defective predicates with logically contradictory ones.

Where, according to Dorr (2005:263), a metaphysically analytic truth is a truth that is true in virtue of the full and complete meaning of its expressions, including their denotations. For example, 'All water is $\mathrm{H}_{2} \mathrm{O}$ ' is a metaphysically analytic truth because everyone who knows the full and complete meaning of 'water' and ' $\mathrm{H}_{2} \mathrm{O}$ ', including which property each one expresses, will know that it is true. In other words, by knowing the full and complete meaning of the expressions involved, one

32 One might suspect that this bifurcation partly explains some of our puzzlement over the modal status of existential mereological truths. 
knows that the fact that all water is $\mathrm{H}_{2} \mathrm{O}$ is the same fact as the fact that all $\mathrm{H}_{2} \mathrm{O}$ is $\mathrm{H}_{2} \mathrm{O}$; but since 'All $\mathrm{H}_{2} \mathrm{O}$ is $\mathrm{H}_{2} \mathrm{O}$ ' is a logical truth, 'All water is $\mathrm{H}_{2} \mathrm{O}$ ' must be true too. The metaphysical analysis of an expression, according to Dorr (2005:261-262), is the most canonical expression of which feature it expresses. In other words, a metaphysical analysis of an expression is a canonical statement of what it is to be what the expression expresses. A metaphysical analysis is thus akin to what is sometimes called a real definition. So, for example, the metaphysical analysis of 'water' is being $\mathrm{H}_{2} \mathrm{O}$. What it is to be water is to be $\mathrm{H}_{2} \mathrm{O}$. Finally, a semantically defective expression, according to Dorr (2005:267-269), is an expression that attempts to express something impossible, and hence fails to express anything. For example, 'phlogiston' is a semantically defective predicate by attempting to express something that arguably in fact turns out to be impossible.

Of course, each one of these notions is problematic in its own way, but we can easily get an intuitive grasp of them, and hence get an intuitive grasp of Dorr's criterion for the language of ontology, which is all we need for present purposes. The criterion simply says that in the language of ontology, by replacing all nonlogical expressions with expressions for what they really express, we obtain logical truths. In the special case of semantically defective expressions, what they really express is impossible, so we replace them with something impossible in the language of ontology as well, namely a logical contradiction.

On the basis of this individuation of the language of ontology, Dorr argues that fundamental nihilism follows, on the assumption that mereological expressions are semantically defective in the language of ontology. Assume mereological expressions are thus semantically defective. Then, by the above criterion, in the language of ontology, they must be replaced by logically contradictory ones. But then they express something impossible, which means there cannot, most fundamentally, be any composite objects, which means nihilism is, most fundamentally, necessarily true.

Of course, as Dorr himself points out, no one will be convinced of this argument unless they are already convinced that mereological expressions are semantically defective in the language of ontology. But that mereological 
expressions are semantically defective in the language of ontology is a reasonable assumption, according to Dorr, on the basis of a lack of metaphysical analyses of them such that we can obtain logical truths from them. ${ }^{33}$

But now consider CAI: $x x C y={ }_{d f} x x=y$, from which we define all other mereological predicates. CAI can be taken to express a metaphysical analysis of mereological composition. That is, by formulating CAI as a definition, one can in effect be taken to be saying what composition is: what it is to compose something is to be identical with it. But surely the predicate for identity is not a semantically defective predicate (self-identity is not impossible!), so neither is the predicate for mereological composition, nor any other mereological predicates that can be well defined on the basis of it. But then, by Dorr's criterion for the language of ontology, we get the necessity of fundamental universalism: by replacing the expression for composition in the wff ' $\forall \mathrm{xx} \exists y(\mathrm{xxCy})$ ' with its metaphysical analysis, we get ' $\forall \mathrm{xx} \exists \mathrm{y}(\mathrm{xx}=\mathrm{y})$ ', which was in section 2 argued at length to be a logical truth. So, on the basis of CAI, in the language of ontology, as individuated by Dorr's criterion, fundamental universalism is necessarily true. That is, by Dorr's criterion, any plurality of things composes something that fundamentally exists.

Dorr (2005:251) claims that any criterion for the language of ontology must discriminate between rival answers to ontological questions. That is, the language of ontology should not entail two rival, incompatible answers to an ontological question on pain of not being the language it is intended to be, namely the language that best represents the fundamental structure of reality. So, one conclusion we might draw from the above result is that Dorr's criterion fails by his own lights to individuate the language of ontology because it fails to discriminate between fundamental nihilism and fundamental universalism. The result is that anyone skeptical about ontological debates being substantive debates will remain thus skeptical.

${ }^{33}$ Dialectically, Dorr (2005:270-273) is only trying to convince the ones who are already skeptical of ontological debates over composite objects being substantive debates. 
But another conclusion we might draw is that Dorr, without CAI on the radar, simply overlooked something. Mereological expressions aren't in fact semantically defective in the language of ontology because by CAI the main reason we had for thinking so is no longer a reason for thinking so. Recall, the main reason to think mereological expressions were defective in the language of ontology was that there seemed to be no plausible candidate for being a metaphysical analysis of them by which we could obtain logical truths. But with CAI now on the radar, we in fact have such a candidate. Given CAI, mereological expressions aren't semantically defective in the language of ontology because they are well defined in terms of identity, which is a predicate that is most certainly not semantically defective. ${ }^{34}$ So, Dorr's criterion actually favors fundamental universalism over nihilism. ${ }^{35}$

But before we draw an overall conclusion from my argument here, let's consider Sider's (2013) argument in favor of mereological nihilism. The same overall conclusion should be drawn from it. Sider argues that, all else being equal, ideological parsimony is a theoretical virtue that counts in favor of one theory's fundamental truth over another. By 'ideology', Sider $(2009,2011,2013)$ means primitive notions by virtue of which the fundamental theory is formulated. The idea might then be that the fewer such primitive notions behind ones fundamental theory, the less structure it requires of reality for its fundamental truth, so the more likely it is to be fundamentally true. So, in particular, if theory $\mathrm{T}$ has no mereological notions in its ideology, but theory $\mathrm{T}^{*}$ does, then, if everything else is equal between

\footnotetext{
${ }^{34}$ One might here object that ' $x \mathrm{x}=\mathrm{y}$ ' is semantically defective even if ' $\mathrm{x}=\mathrm{y}$ ' and ' $\mathrm{x} x=\mathrm{y} y$ ' are not. But that concerns the very coherence of CAI. I here only argue that if one brings CAI on board, assuming it is coherent, Dorr's argument fails. Thanks to Aaron Cotnoir on this point.

35 Dialectically, anyone skeptical of ontological debates over composite objects being substantive debates should now, by encountering Dorr's criterion for the language of ontology together with CAI, be convinced that fundamental universalism is necessarily true. One might also argue that it is more faithful to the practice of ontology to treat mereological expressions as not being semantically defective, which would tilt in favor of fundamental universalism over nihilism, by Dorr's criterion. Such faithfulness is another requirement Dorr (2005:251) claims for the criterion for the language of ontology to be successful. Another aside: it would be interesting to try to turn Dorr's entire argument into an argument in favor of CAI and unrestricted composition.
} 
them, theory $\mathrm{T}$ is more likely to be fundamentally true than theory $\mathrm{T}^{*}$. Now, Sider argues at length that everything else is equal between a fundamental theory with and a fundamental theory without mereological notions in its ideology. I have no wish to contest that result. But Sider seems to assume that a fundamental theory without any mereological notions in its ideology is a theory that entails mereological nihilism being fundamentally true; that I wish to contest.

A theory without mereological primitives in its ideology does not entail the fundamental truth of nihilism because by CAI we have no mereological primitives in our ideology, but nonetheless we have the fundamental truth of universalism. Sider's argument from ideological parsimony thus does not by itself favor fundamental nihilism over fundamental universalism.

The proponent of Sider's argument might of course object that all else is not equal if we bring onboard CAI. She might argue, for example, that by bringing onboard CAI we end up with a more complicated fundamental theory by virtue of needing a numerically hybrid identity, rather than just ordinary singular identity. From that she might argue that nihilism is therefore more likely to be fundamentally true. But it is not clear how to assess this objection. First of all, by bringing on board CAI one is not bringing on board more laws of identity than the standard ones; $R$ and PII are all the laws of identity one needs. So one only has the one primitive notion of identity uniquely determined by these two laws, and hence seemingly no additional fundamental structure. Second, considerations of parsimony must be overall-considerations. In the absence of mereology in ones ideology, a proponent of Sider's argument seems to need set-theoretical notions in her ideology in order to gain sufficient expressive powers (Sider, 2013:section 11). But with mereology in one's ideology, one might not need set-theoretical notions in one's ideology (Lewis, 1991:especially appendix, 1993b). And given CAI, one can define and logically deduce all the expressive powers of mereology that one wants, and so without any primitive mereological notions in one's ideology. ${ }^{36}$ So, in fact, it might turn out, by overall-considerations, that we can do without both set-theoretical and

${ }^{36}$ Given that my argument for unrestricted composition in section 2 is right, all of classical mereology can be deduced on the basis of CAI. See Sider (2007:60-62). 
mereological primitives in our ideology, given CAI. So, if definitions and theorems of a fundamental theory are parts of the fundamental theory, it seems the argument from parsimony favors fundamental universalism by virtue of CAI, not fundamental nihilism.

One might object that definitions are cheap, so what can be defined on the basis of a fundamental theory is not part of that fundamental theory itself, and hence that, by CAI, mereology is no part of fundamental theory, and hence neither is unrestricted composition. This is an argument from syntactic parsimony, not ideological parsimony. But, as is well known, syntactic parsimony is cheap, and carries little, if any force by itself. So, an argument from syntactic parsimony carries little, if any force by itself (and in any case it might be outweighed by the above possible overall considerations). Second, even if successful, CAI shows that the objection still doesn't get us to fundamental nihilism without additional premises.

So, one conclusion to draw from the above discussion of both Dorr's and Sider's arguments is that both arguments are invalid. Dorr's argument for nihilism is invalid (by monotonicity) because by merely adding CAI as a premise, the argument entails unrestricted composition. Sider's argument for nihilism is invalid because without additional premises, it entails nihilism or CAI's version of unrestricted composition.

But there is also a second conclusion to draw: the proponents of the arguments are operating with a thick notion of existential quantification. They treat the fundamental existential quantifier as something equivalent to expressing a property of properties that are instantiated by objects, where by 'object' they mean something belonging to (perhaps perfectly) natural sorts of things. That is, they have simply somehow restricted their fundamental existential quantifier to only range over certain sorts of things. But then, by the above bifurcation, there is a way to reconcile their conclusion of nihilism with CAI and its resulting form of unrestricted composition. The fact that all the Fs are mereological simples is compatible with the conclusion that any plurality of $F$ s composes something because the composed things need not themselves be Fs. So, if we restrict our fundamental existential quantifier to only range over certain sorts of things, then 
the conclusion that the most natural sorts of things are mereological simples is perfectly compatible with the conclusion that any plurality of things composes something that fundamentally exists. So, as above, we get a form of fundamental universalism coupled with perfectly natural nihilism: the most natural sorts of things are mereological simples, but nonetheless, any plurality of things composes something that fundamentally exists. ${ }^{37}$

\section{CONCLUSION}

Peter van Inwagen (1990:30) asked the special composition question: under what conditions is ' $\exists y(x x C y)$ ' satisfied? By CAI, I have answered: under the same conditions as ' $\exists y(x x=y)$ ' is satisfied, which is under the same conditions as ' $\mathrm{xx}=\mathrm{xx}$ ' is satisfied, which is necessarily always. Peter van Inwagen (1990:39) also asked the general composition question: what is composition? By CAI, I have answered: identity. ${ }^{38}$ None of these two questions requires a thick notion of existential quantification in order to be answered, neither fundamentally nor necessarily. And what's more, none of these two questions is the same question as the one we asked earlier: what is the mereological structure of the most natural sorts of things there are? On this last question, CAI simply remains silent. I suspect that many haven't

37 A problem with the above arguments for nihilism thus understood is of course that the restriction in question seems to be to mereological simples, which makes the arguments suspiciously circular. But let that be as it may for present purposes. Exactly what the restriction is, and how they get it, is just not clear. Note that Sider $(2009,2011)$ argues against the fundamental quantifier being a mere restriction on the more ordinary quantifiers. For him, the fundamental quantifier is a primitive matter. But still, it is just not clear how that leads to nihilism as per Sider (2013).

38 It should go without saying that the fact that CAI so clearly provides necessary answers to both the special and the general composition question counts heavily in its favor. Arguably, by principles of Humean re-combination, there is no way to provide a metaphysically necessary answer to the special composition question apart from CAI or nihilism (cf. Bohn, ms). Also, as far as I know, there just is no plausible, non-tautological candidate for being an answer to the general composition question apart from CAI and nihilism. In both cases, CAI is to be favored over nihilism simply because of its additional expressive powers. 
been sufficiently clear on the difference between this last question and the special composition question as such. ${ }^{39}$

\section{BIBLIOGRAPHY}

- Armstrong, D. (1978). A Theory of Universals: Universals and Scientific Realism Vol. II. Cambridge University Press.

- ---------- (1997). A World of States of Affairs. Cambridge.

- Barwise, J. \& Cooper, R. (1981). Generalized Quantifiers and Natural Language. As in Portner \& Partee (2002).

- Baxter, D. (1988a). Identity in the Loose and Popular Sense. Mind, New Series, Vol.97, No.388, pp. 575-582.

- -------- (1988b). Many-One Identity. Philosophical Papers, Vol. XVII, No.3, pp. 193-216.

- Beaney, M. (ed.) (1997). The Frege Reader. Blackwell.

- Bohn, E. D. (2009). Composition as Identity. Doctorial dissertation. UMass Amherst.

- --------- (2011). Commentary on "Parts of Classes". Humana.Mente, vol.19, pp.151-158.

- ----------- (2012). Monism, Emergence, and Plural Logic. Erkenntnis, Vol. 76, No. 2, pp. 211-223.

- --------- (ms). From Hume's Dictum to Composition as Identity or Mereological Nihilism.

- Boolos, G. (1984). To Be is to Be the Value of a Variable (or to Be Some Values of Some Variables). As in Boolos (1998).

- --------- (1985). Nominalistic Platonism. As in Boolos (1998).

\footnotetext{
${ }^{39}$ Special thanks to Donald Baxter, Phillip Bricker, Ben Caplan, Aaron Cotnoir, Edward Ferrier, Torfinn Huvenes, Toby Napoletano, Jonathan Schaffer and audiences at the University of Massachusetts Amherst, the University of Nottingham, the University of St Andrews, and the University of Oslo. Thanks also to all students, friends and colleagues I have discussed these and similar ideas with over the last five years or so.
} 
- $\quad$---------- (1998). Logic, Logic, and Logic. Harvard University Press.

- Cameron, R. (2012). Composition as Identity Doesn't Settle the Special Composition Question. Philosophy and Phenomenological Research Vol. LXXXIV, No. 3, pp.531-554.

- Chalmers, D., Manley, D., \& Wasserman, R. (eds.) (2009). Metametaphysics. Oxford.

- Cotnoir, A. (forthcoming). Composition as General Identity. Oxford Studies in Metaphysics.

- Dorr, C. (2005). On what we disagree about when we disagree about ontology. As in Kalderon (2005).

- Frege, G. (1884). The Foundations of Arithmetic. Blackwell. As translated by J. L. Austin (1980).

- ------- (1892). On Concept and Object. As in Beaney (1997).

- Gabbay, D.M. \& Guenthner, F. (eds.) (2007). Handbook of Philosophical Logic. $2^{\text {nd }}$ edition, Vol. 14, pp. 223-338. Springer.

- Heim, I. \& Kratzer, A. (1998). Semantics in Generative Grammar. Blackwell.

- Kalderon, M.E. (ed.) (2005). Fictionalism in Metaphysics. Oxford University Press.

- Leonard, H. S. \& Goodman, N. (1940). The Calculus of Individuals and Its Uses. The Journal of Symbolic Logic, Vol. 5, No. 2, pp. 45-55.

- Lewis, D. (1970). General Semantics. As in Lewis (1983b).

- --------- (1983a). New Work for a Theory of Universals. As in Lewis (1999).

- --------- (1983b). Philosophical Papers. Oxford University Press.

- -------- (1986). On the Plurality of Worlds. Blackwell.

- ---------- (1988). Rearrangement of particles: reply to Lowe. As in Lewis (1999).

- ---------- (1991). Parts of Classes. Blackwell.

- -------- (1993a). Many, but almost one. As in Lewis (1999).

- --------- (1993b). Mathematics is megethology. As in Lewis (1998).

- --------- (1998). Papers in Philosophical Logic. Cambridge University Press.

- --------- (1999). Papers in Metaphysics and Epistemology. Cambridge. 
- McDaniel, K. (2008). Against Composition as Identity. Analysis 68.2, pp. 128133.

- ------------ (2010). Composition as Identity Does Not Entail Universalism. Erkenntnis Vol.73, No.1, pp. 97-100.

- Montague, R. (1973). The Proper Treatment of Quantification in Ordinary English. As in Portner \& Partee (2002).

- Mostowski, A. (1957). On a generalization of quantifiers. Fundamenta Mathematicae 44, pp. 12-36.

- Portner, P. (2005). What is Meaning? Blackwell.

- Portner, P. \& Partee, B. (eds.) (2002). Formal Semantics. Blackwell.

- Quine, W.V.O. (1966). The Ways of Paradox and other essays. Harvard University Press.

- Rayo, A. \& Uzquiano, G. (eds.) (2006). Absolute Generality. Oxford.

- Sider, T. (2007). Parthood. Philosophical Review 116: pp. 51-91.

- ------- (2009). Ontological Realism. As in Chalmers et. al. (2009).

- $\quad$-------- (2011). Writing the Book of the World. Oxford.

- --------- (2013). Against Parthood. Oxford Studies in Metaphysics, Vol. 8.

- -------- (this volume). Consequences of Collapse.

- Van Inwagen, P. (1990). Material Beings. Cornell.

- - ------------- (1994). Composition as Identity. As in van Inwagen (2001).

- - ---------- (2001). Ontology, Identity, and Modality. Cambridge.

- Wallace, M. (2011a). Composition as Identity Part I. Philosophy Compass, 6 (11), pp.804-816.

- ---------- (2011b). Composition as Identity Part II. Philosophy Compass, 6 (11), pp. 817-827.

- Westerståhl, D. (2007). Quantifiers in Formal and Natural Languages. As in Gabbay \& Guenthner (2007).

- Williamson, T. (2006). Absolute Identity and Absolute Generality. As in Rayo \& Uzquiano (2006).

- Yi, Byeong-Uk (1999). Is Mereology Ontologically Innocent? Philosophical Studies 93, pp. 141-160. 
- --------------- (2005). The Logic and Meaning of Plurals: Part I. Journal of Philosophical Logic 34, pp. 459-506.

- -------------- (2006). The Logic and Meaning of Plurals: Part II. Journal of Philosophical Logic 35, pp. 239-288. 